\title{
$\widehat{A}_{\text {Bochimica }}^{\text {Bolonica }}$
}

Vol. 48 No. 3/2001

$783-793$

QUARTERLY

\section{Comparative studies of nuclear DNA content in benign and malignant thyroid lesions}

\author{
Liliana Konarska ${ }^{1 \bowtie}$, Janusz Skierski ${ }^{2}$, Aleksandra Ellert ${ }^{1}$, Justyna Steinbrich ${ }^{1}$, \\ Agnieszka Woźniak ${ }^{1}$ and Mirosław Kałczak ${ }^{3}$ \\ ${ }^{1}$ Department of Biochemistry and Clinical Chemistry, University Medical School of Warsaw, \\ Warszawa, Poland; ${ }^{2}$ Flow Cytometry Laboratory, Drug Institute, Warszawa, Poland; \\ ${ }^{3}$ Department of Pathomorphology, MSWiA Hospital, Warszawa, Poland
}

Received: 29 July, 2001; revised: 23 August, 2001; accepted: 5 September, 2001

Key words: DNA content, DNA index, ploidy, proliferative index, flow cytometry, paraffin-embedded tissue, thyroid

Currently available data suggest that DNA aneuploidy is associated with aggressive behavior of and unfavorable prognosis in several malignant human tumors as compared with diploid malignancies. However, the diagnostic and prognostic importance of flow cytometric DNA measurements in the case of thyroid neoplasms remains controversial. Therefore, the aim of our study was to evaluate utility of DNA index (DI) and proliferative index (PI) in distinguishing benign from malignant thyroid lesions taking into account the possible influence of intra-tumor heterogeneity and tissue preparation mode on DNA flow-cytometry measurements.

A retrospective study was performed on 71 paraffin-embedded specimens from 57 patients with benign and malignant thyroid pathologies: 13 colloid goitres, 12 parenchymatous goitres, 19 adenomas and 13 carcinomas. In 14 of 57 cases two separate specimens taken from different areas of the same lesion were analysed and DNA parameters were compared. Additionally, flow cytometry DNA analysis was parallelly performed on 3 adjacent but differently processed tissue sections (fresh, formalin-fixed and paraffin-embedded) taken from each of 26 surgically excised thyroid lesions. DNA content was also analysed in both fresh and formalin-fixed twin specimens of normal pig thyroid glands $(N=6)$.

We demonstrated that all tumors diagnosed as thyroid carcinomas were associated with abnormal nuclear DNA content although aneuploidy was not found specific to malignant thyroid tumors. Aneuploid samples of benign thyroid lesions exhibited higher proliferative activity, expressed as mean PI values, than diploid ones. In carcinomas the mean PI values were significantly higher than in benign lesions, independently whether they concerned aneuploid or diploid tissues. Considering intra-tumor heterogeneity, the flow cytometric DNA parameters can be assumed as reproducible despite differences in the mode of tissue fixation and preparation for analysis.

${ }^{\circledR}$ To whom correspondence should be addressed: e-mail: konarska@nencki.gov.pl Abbreviations: DI, DNA index; PI, proliferative index. 
Numerous cytogenetic studies have demonstrated abnormal nuclear DNA content (aneuploidy) and increased number of cells in the S-phase in the majority of human malignant tumors [1-5]. Flow cytometric DNA studies of fresh tissue samples and retrospective analysis of paraffin-embedded specimens have shown aneuploidy to be associated with aggressive tumor behavior and poor prognosis in ovarian [2, 6], breast [3], colorectal [7], prostatic [8], non-small-cell lung [9] and gastric [1] cancers. Some authors have shown a correlation between flow cytometric parameters (such as fraction of cells in the S-phase and ploidy level) and the tumor malignancy as well as the tumor differentiation grade in a sequence from benign neoplasms to aggressive malignant cancers $[5,10,11]$.

Nevertheless, clinical importance of this method is still controversial [12, 13]. The prognostic value of flow cytometric DNA analysis is considered to be useful only in the early period of a disease $[2,4,8,12,14]$. In the advanced stage of ovarian [6] or breast [13] cancers the measurement of DNA content and mitotic cycle analysis in tumor cells are believed to be of low diagnostic value.

Recently, DNA analysis by flow cytometry has also been adapted for evaluation of various thyroid hyperplastic changes. Neoplasms of this gland seem to be attractive models for studing molecular aspects of carcinogenesis, as they represent a wide range of phenotypes from benign goitres, through non-aggressive colloid adenomas to invasive anaplastic cancers, associated with poor prognosis. On the other hand, the conventional diagnostic techniques are still insufficient for early differential diagnosis and/or prognosis of thyroid gland pathologies [15]. Generally, distinguishing benign from potentially malignant primary endocrine tumors is of great importance from the clinical and therapeutic point of view. However, it is claimed to be extremely difficult to achieve it on the basis of histomorphologic criteria, especially in certain thyroid pathologies, such as atypical ad- enomatous and non-invasive follicular carcinomas [10, 16] or tumors of histologically benign appearance but producing metastases and referred to as "benign metastizing goitres" [17]. A few published data on flow cytometric analysis of DNA from fresh [18] or fixed [10, 19-25] thyroid tissues are usually limited to narrow histological groups and do not permit to establish the value of this method in differential diagnosis and evaluation of thyroid lesions.

The aim of our study was, therefore, to assess intra- and inter-tumor heterogeneity of DNA flow cytometric parameters (DNA index, proliferative index) in different types of thyroid gland pathologies and to evaluate the possible significance of such analysis in differentiation of benign from malignant cases. Besides, we tried to determine the influence of tissue fixation and cell preparation procedures on the reliability of DNA cytometric parameters.

\section{METHODS}

Flow cytometry DNA analysis was performed on surgically excised fresh $(\mathrm{N}=26)$ and archival paraffin-embedded $(\mathrm{N}=71)$ thyroid tissues obtained from pathomorphology department of MSWiA Hospital in Warsaw. Individual cases $(\mathrm{N}=57)$ of benign and malignant thyroid lesions were classified into four groups, based on routine histopathologic typing: colloid goitres $(\mathrm{N}=13)$, parenchymatous goitres $(\mathrm{N}=12)$, adenomas $(\mathrm{N}=19)$ and carcinomas $(\mathrm{N}=13)$. In 14 of 57 cases two separate specimens were taken from different areas of the same thyroid lesion, a central and an adjacent (further refered to as peripheral), for paraffin blocks preparation and further histopathologic typing and DNA analysis. Four sections were cut from each paraffin block and two of them, the first and third ( $5 \mu \mathrm{m}$ thick), were submitted to routine histologic examination or verification. The second and fourth sections (80 $\mu \mathrm{m}$ thick) were used for DNA 
analysis. In 26 cases, the cytometric DNA analysis was additionally performed on 3 adjacent sections of the same thyroid lesion, which were treated differently after the resection: used fresh (unfixed) or fixed with formalin or formalin-fixed and paraffin-embedded.

Single-cell suspensions from paraffin-embedded tissues were prepared as described by Hedley et al. [26]. Briefly, two $80 \mu \mathrm{m}$ sections were placed at $60^{\circ} \mathrm{C}$ for $10 \mathrm{~min}$ and then were cleaned of paraffin in xylene and rehydrated in a series of solutions with decreasing concentrations of ethanol $(100 \%$, $95 \%, 70 \%$ and $50 \%$ ) and finally in distilled water at room temperature. The rehydrated slices were suspended in 0.5\% pepsin (Sigma Chemical Co.) in $0.9 \% \mathrm{NaCl}, \mathrm{pH} 1.5$, and incubated at $37^{\circ} \mathrm{C}$ for 30 min with vortexing at 5 -min intervals. The cell suspension was centrifuged at $200 \times \boldsymbol{g}$ for $10 \mathrm{~min}$ at $4^{\circ} \mathrm{C}$ and the pellet of cells was then washed and resuspended in $0.2 \mathrm{ml}$ of phosphate-buffered saline (PBS). Similarly to paraffin-embedded tissues, fresh or formalin-fixed specimens were subjected to pepsin proteolysis to form single cell suspensions. Isolated cells were stored in $70 \%$ ethanol at $4^{\circ} \mathrm{C}$. Prior to analysis the cell suspension was filtered through a nylon mesh to remove any debris and cell aggregates.

To establish the normal diploid DNA peak position, purified human peripheral blood lymphocytes were used as a reference. In addition, to compare the results of different tissue preparations, DNA content was analysed both in fresh or formalin-fixed specimens of normal pig thyroid glands $(\mathrm{N}=6)$, using pig peripheral blood lymphocytes as a standard.

All samples were analysed with FACS Vantage flow cytometer (Becton Dickinson), equipped with an argon-ion laser, emitting excitation light in visual and UV bands. Cells were stained with 4',6'-diamidino-2-phenylindole (DAPI) (Polysciences Inc.) and sulforhodamin (SR) (Molecular Probes Inc.) as described earlier [27]. The cells were excited at $351 \mathrm{~nm}$ and fluorescence was measured at 460-520 nm (for DAPI) or at $>600$ nm (for SR). At least 10000 cells were evaluated from each tissue sample to construct an individual DNA histogram.

The relative DNA content (ploidy level) was expressed as DNA index (DI) calculated as a ratio: G0-G1 peak of a sample/G0-G1 peak of a reference cell population on a histogram. For normal DNA content (diploidy) DI = $1.0 \pm 0.1$. Cells exhibiting DI $\neq 1.0 \pm 0.1$ were classified as aneuploid; hyperdiploid when DI $>1.1$ or hypodiploid when DI < 0.9. Samples exhibiting a bimodal DNA content pattern on histograms were referred to as multiploid.

Histogram analysis, cell cycle stage and the percentage of tumor cells remaining in each phase of the cell cycle were performed and established using MacCycle computer program. Tumor proliferative activity was expressed in terms of calculated percentage of cells in S-phase and proliferative index (PI $=\%$ of the cells in S-phase + \% of the cells in G2/Mphase). The data were analysed statistically by the Student's $t$-test.

\section{RESULTS}

The DNA index values counted for 71 paraffin-embedded thyroid specimens ranged from 0.39 to 1.66 . Over $62 \%$ of all examined tissues exhibited DI values below 0.9 , corresponding to hypodiploid DNA content, while $4 \%$ were hyperdiploid (DI > 1.1), 13\% multiploid (containing two cell populations of different DI values) and only $21 \%$ were diploid (DI $=1.0 \pm$ 0.1). The distribution of DNA index values and DNA ploidy in four histopathological groups studied is reported in Fig. 1 and Table 1 , respectively.

In 16 samples of colloid goitre DI ranged from 0.43 to 1.09 (mean $0.79 \pm 0.15$ ). The majority (69\%) of the tissues was classified as hypodiploid, $12 \%$ as multiploid and only $19 \%$ as diploid. Similarly, in 15 sections of parenchymatous goitres DI reached the mean value of $0.81 \pm 0.14$ (range 0.68-1.09) and $73 \%$ of the samples showed hypodiploid DNA 


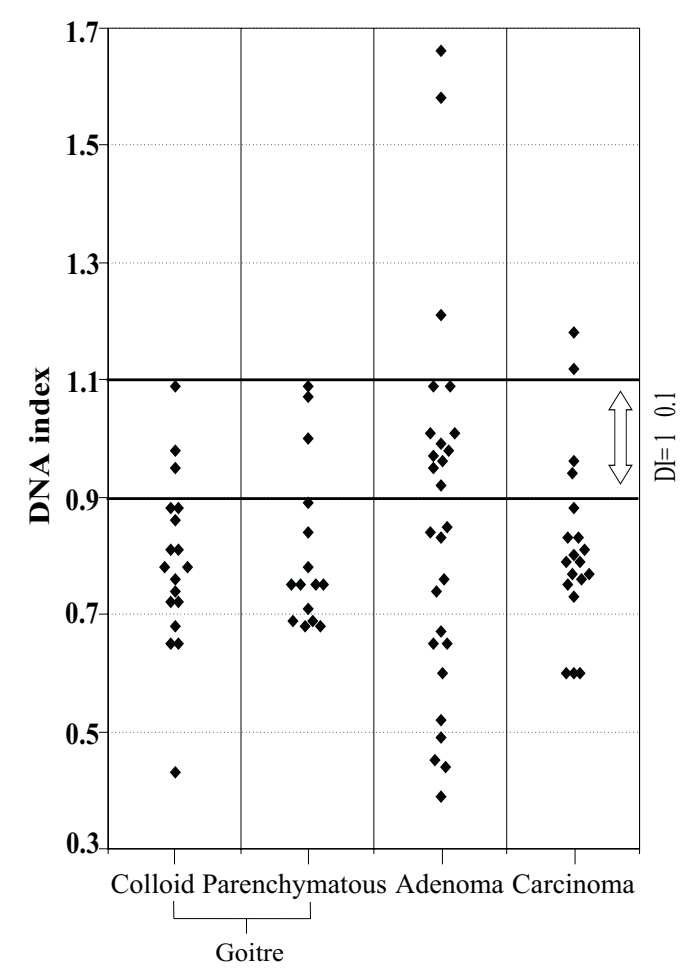

Figure 1. Distribution of DNA index values in four groups of thyroid pathologies: colloid and parenchymatous goitres, adenomas and carcinomas.

content, $7 \%$ was multiploid, whereas only $20 \%$ exhibited DI value of $1.0 \pm 0.1$. In adenomas DI ranged from 0.39 to 1.66 with an average of $0.86 \pm 0.31$. Diploidy was detected in 7 (32\%) of 22 specimens, 9 of which (41\%) were hypodiploid, 1 (4\%) hyperdiploid and 5 (23\%) multiploid. All 13 tumors diagnosed as thyroid carcinomas exhibited an abnormal DNA content (detected at least in one section of a tumor). In this group DI values ranged from
0.6 to 1.18 with an average of $0.82 \pm 0.1$. Thirteen $(72 \%)$ of 18 analysed carcinoma samples were hypodiploid, 2 (11\%) were hyperdiploid and one (6\%) multiploid. Two of 5 cancers from which two separate samples for DNA analysis were taken from different tumor areas exhibited diploid amount of DNA in one of two scanned samples (Fig. 2). These diploid samples constituted only $11 \%$ of all analysed carcinoma specimens.

In each of four histological groups of thyroid lesions DNA multiploidy was detected (Table 1). As it is depicted in Fig. 3, each of three multiploid goitres (two colloid goitres and one parenchymatous goitre) expressed two different hypodiploid cell populations. Histograms of five examined adenoma tissues also showed a bimodal cell distribution pattern with at least one aneuploid population in each case. In carcinoma group one tumor showed a multiploid pattern with two hypodiploid cell populations.

In an attempt to further evaluate intra-tumor heterogeneity, in 14 of 57 cases ( 3 colloid and 3 parenchymatous goitres, 3 adenomas and 5 carcinomas) two separate tissue samples isolated from different areas (central and peripheral) of each tumor or goitre were used for DNA analysis. Only 2 (66\%) of colloid and $2(66 \%)$ of parenchymatous goitres, $1(33 \%)$ of adenomas and 2 (40\%) of carcinomas appeared to be homogeneous since both of the examined specimens of each tumor expressed the same DNA ploidy, both diploid or both hypodiploid (Fig. 2). Adenomas and carcinomas revealed more heterogeneous pattern of

Table 1. DNA ploidy distribution in different histopathological groups of benign and malignant thyroid lesions

\begin{tabular}{|c|c|c|c|c|c|}
\hline \multirow{2}{*}{$\begin{array}{l}\text { Histopathological } \\
\text { groups }\end{array}$} & \multirow{2}{*}{ Total } & \multicolumn{4}{|c|}{ DNA ploidy distribution } \\
\hline & & diploid & hypodiploid & hyperdiploid & multiploid \\
\hline Colloid goitre & 16 & $3(19 \%)$ & $11(69 \%)$ & 0 & $2(12 \%)$ \\
\hline Parenchymatous goitre & 15 & $3(20 \%)$ & $11(73 \%)$ & 0 & $1 \quad(7 \%)$ \\
\hline Adenoma & 22 & 7 (32\%) & $9(41 \%)$ & $1 \quad(4 \%)$ & $5(23 \%)$ \\
\hline Carcinoma & 18 & $2(11 \%)$ & $13(72 \%)$ & $2(11 \%)$ & $1 \quad(6 \%)$ \\
\hline
\end{tabular}

Number of analysed samples (\% of total) are given 


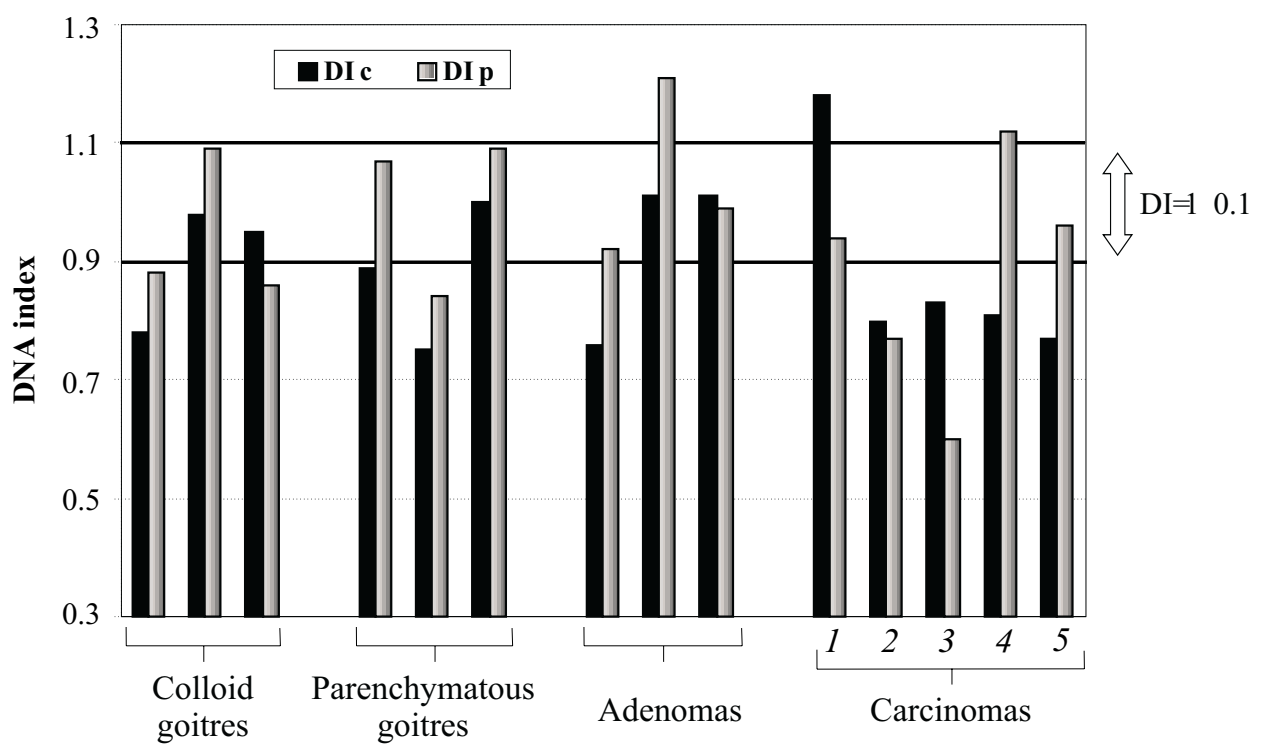

Figure 2. Intra-tumor heterogeneity of nuclear DNA content.

DNA index values were determined in two separate tissue sections taken from different, central $\left(\mathrm{DI}_{\mathrm{c}}\right)$ and peripheral $\left(\mathrm{DI}_{\mathrm{p}}\right)$, areas of each tumor. 1, follicular carcinoma; 2 and 3, adenocarcinomas; 4, papillary carcinoma; 5, anaplastic carcinoma.

cellular DNA content than colloid and parenchymatous goitres.

Based on the cell cycle analysis, the cell cycle phase distribution and the values of proliferative index (PI) were determined for different thyroid lesions (Table 2). Aneuploid tissue samples exhibited higher PI values than diploid ones in all 3 pathomorphological groups of benign thyroid lesions. In contrast, carcinomas exhibited high PI values independently whether they were aneuploid or diploid.

The results of flow cytometric DNA analysis were additionally evaluated in differently pro- cessed tissue preparations. In 26 cases, DNA ploidy was assessed in fresh, formalin-fixed and paraffin-embedded specimens taken from the same thyroid lesion. Aneuploid DNA pattern was detected in 12 (46\%) fresh specimens, in 11 (42\%) formalin-treated and 12 (46\%) paraffin-embedded specimens. Fifty percent of formalin-fixed and $50 \%$ of paraffin-embedded tissues showed parallel DNA ploidy when compared with fresh material. DI similarity between formalin-fixed and paraffin-embedded specimens of the same tissue was observed in $61 \%$ of cases. The results of DNA analysis and correlation between DI val-

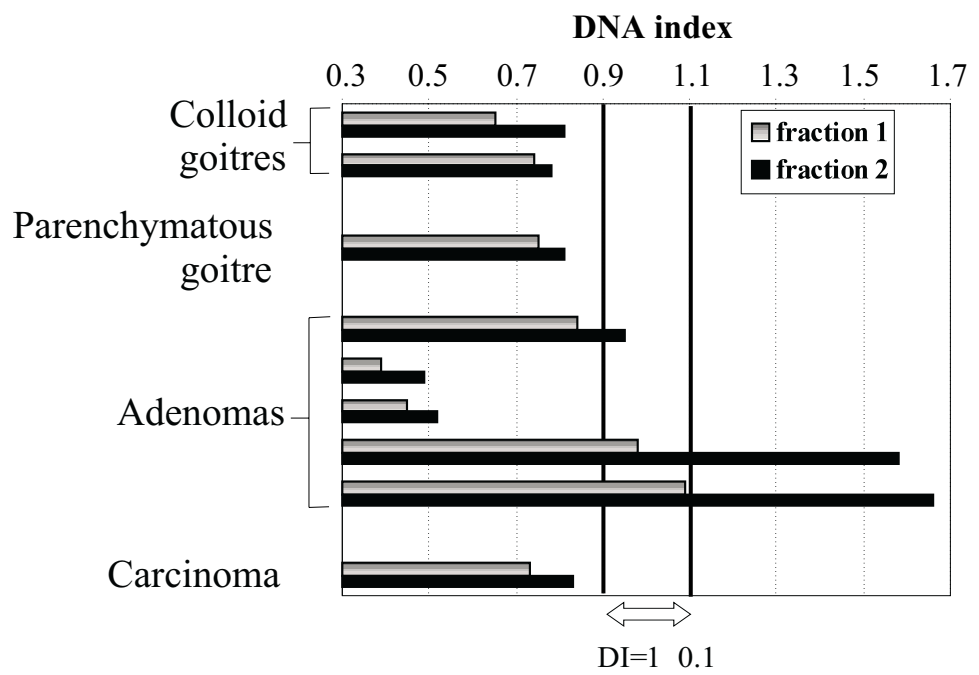

Figure 3. Multiploidy of thyroid tumors representing various histopathological groups.

Two cell populations of different DNA content (fraction 1 and fraction 2) were detected on histogram of each examined sample. 
Table 2. Proliferative index values (PI) of diploid and aneuploid cell fractions from benign and malignant thyroid lesions

\begin{tabular}{lrcccccc}
\hline \multirow{2}{*}{ Histopathological groups } & \multicolumn{3}{c}{ Diploid } & \multicolumn{3}{c}{ Aneuploid } \\
\cline { 2 - 7 } & $\mathrm{N}$ & mean & range & $\mathrm{N}$ & mean & range \\
\hline Colloid goitre & 3 & 8.6 & $(3.5-17.7)$ & 15 & $13.7^{*}$ & $(3.3-23.5)$ \\
Parenchymatous goitre & 3 & 3.7 & $(0-11.0)$ & 13 & $6.7^{*}$ & $(0-35.9)$ \\
Adenoma & 11 & 8.4 & $(0-24.2)$ & 16 & $10.2^{* *}$ & $(0-24.5)$ \\
Carcinoma & 2 & 19.4 & $(8.5-30.3)$ & 17 & 16.2 & $(3.1-52.1)$ \\
\hline
\end{tabular}

$\mathrm{PI}=\% \mathrm{~S}+\% \mathrm{G} 2 / \mathrm{M} .{ }^{*} P<0.01 ;{ }^{*} P<0.05$ - significantly different from the diploid cell fraction

ues in differently processed samples of the same lesion are depicted in Fig. 4.

Besides experiments with samples from human thyroid lesions, comparative measurements of nuclear DNA content were carried out on fresh or formalin-fixed specimens of normal thyroids of 6 pigs (not shown). All examined tissues were diploid with DNA index values ranging from 0.98 to 1.0 as determined in both fresh and fixed samples.

\section{DISCUSSION}

The conventional methods used for diagnosis of most solid tumors are based on architec-

A

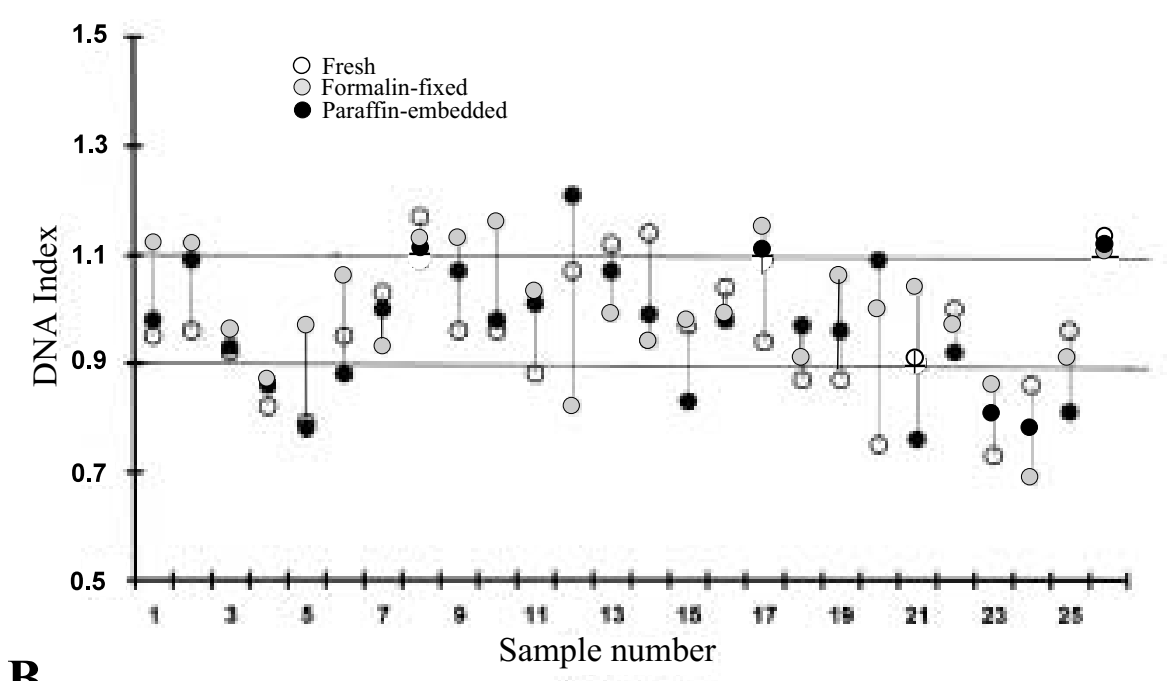

B

A
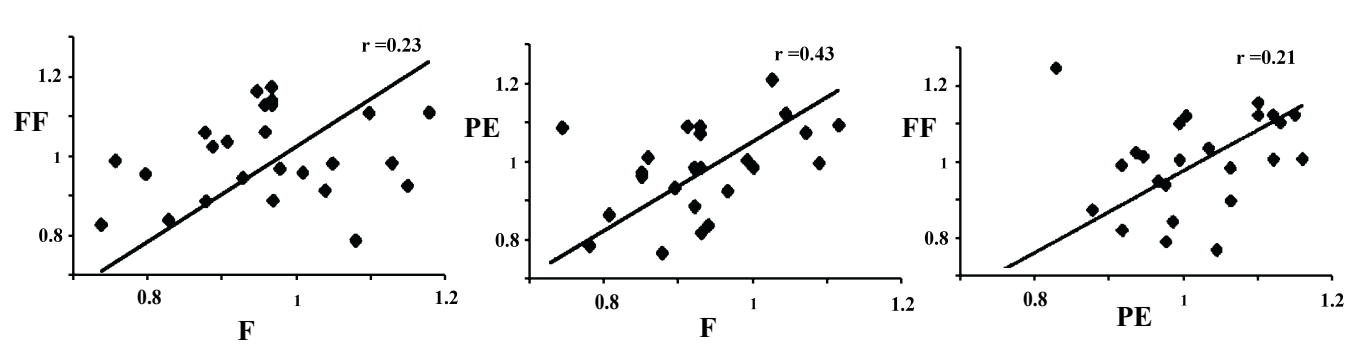

Figure 4. Influence of tissue fixation and processing on DNA flow cytometric measurements.

Distribution of DNA index values determined in 3 differently prepared specimens from each of 26 surgically excised thyroid tumors (A) and plots of correlation between DI values estimated in fresh (F), formalin-fixed (FF) and paraffin-embedded (PE) specimens (B). 
tural and cytological features of a tissue specimen. Therefore the evaluation of some poorlycharacterised types of tumors such as primary endocrine lesions is a challenge for histopathological interpretation. Since reliable and rapid differentiation between benign and malignant tumors is of importance for therapeutic and prognostic reasons, the clinical application of the DNA measurement and cell cycle analysis has been under investigation for several years.

Currently available data suggest that in most solid tumors aneuploidy and high proliferative index may be of significant prognostic value [1, 2, 7, 8, 26]. However, clinical importance of DNA cytometric measurements of thyroid neoplasms remains controversial [18, 19, 21, 22, 24, 25]. Joensuu et al. [22] have found DNA aneuploidy to be associated with poor prognosis in papillary, follicular and medullary carcinomas. Some investigators claim a strict correlation between aneuploid DNA content in thyroid cells and tumor stage and behavior [25, 26]. Alterations in DNA ploidy have been observed in $40 \%$ of the tumors infiltrating extrathyroidal tissues, in contrast to non-invasive tumors that were all diploid [28]. Intensive tumor growth was observed rather in aneuploid than in diploid tumors [29]. Studies on differentiated tumors showed that the anaplastic transformation occurred only in DNA-aneuploid group [10, 29]. Many authors have noticed aneuploidy to be statistically more frequent in anaplastic carcinomas than in differentiated lesions [18, 25, 29]. Comparing the features of benign and potentially lethal thyroid lesions Francia et al. [18] have detected higher percentage of specimens with improper DNA content in the group of malignant tumors. From a variety of examined thyroid lesions Salmon et al. [10] assessed the sequence, in which incidence of diploid cases decreased from multinodular goitres through adenomas down to anaplastic carcinomas. Furthermore, Hoestetter et al. [21] have suggested that DNA index is of diagnostic value in distinguishing benign from malignant pathological changes of the gland. Other authors were less optimistic. Joensuu et al. [23] determined DNA content in follicular adenomas and adenomatous goitres. They suggested that aneuploidy was a common feature in histologically benign thyroid lesions and did not appear to be associated with adverse prognosis. In studies by Cusick et al. [19] and McLeod et al. [30] the frequency of DNA aneuploidy in apparently benign and in malignant thyroid neoplasms appeared to be parallel. Moreover, these authors suggested little clinical relevance of the cell cycle analysis in distinguishing benign from malignant tissues.

Our results indicate that DNA ploidy does not seem to be useful in distinguishing benign from malignant thyroid tumors, especially on the basis of a single sample measurement. Flow cytometric DNA analysis has been carried out on 71 paraffin-embedded archival tissues with histopathological appearance of colloid goitres, parenchymatous goitres, adenomas and carcinomas. Comparative analysis of DNA content in distinct pathomorphological conditions showed high dispersion of DNA index values in both benign and malignant groups of thyroid pathologies. Aneuploidy was not found specific to any type of thyroid lesions and therefore could not be of clinical value. However, all of the thyroid cancers, of which two specimens were studied, expressed the aneuploid DNA pattern at least in one of the two specimens. Therefore, as suggested by Horii et al. [31], detection of abnormal DNA content should incline further investigations in terms of growing probability of malignant disease.

In our study diploid DNA content was found only in $21 \%$ of all examined specimens. Majority of the tissues (over $62 \%$ ) were hypodiploid, $4 \%$ hyperdiploid and $13 \%$ multiploid. Comparing the frequency of aneuploidy in the present and other flow cytometric studies we have noticed a high percentage of hypodiploid tissues. Such a ratio may have resulted from differences in tissue processing and staining, 
the number of nuclei scanned and, first of all, from differences in interpretation of individual DNA histograms [32]. The criteria for aneuploidy determination are not uniform. Thus, the observed additional or disfigured G0/G1 peaks or significant increase in S- or G2/M-phase fractions may imitate abnormal DNA content. Histogram analysis may also be complicated by overlaping of mitotic cycle phases of distinct cell lines. It should be mentioned that majority of reported data referred to a defined type of thyroid lesions [18-20, 22, $23,30]$. In our study flow cytometric DNA analysis was applied to wide spectrum of the most common thyroid pathologies.

Tumor heterogeneity is another important diagnostic problem. Occurrence of more than one cell population within the lesion may cause misinterpretation of cytogenetic features of the whole tumor [32]. In our studies 9 of analysed histograms presented bimodal pattern of DNA content, indicating heterogeneous cell composition of a single tissue sample. Moreover, in 14 cases, chosen as examples of the four histopathological groups, DNA analysis was performed on two independent cell samples obtained from central and adjacent part of the same lesion. Only 7 (50\%) of examined tumors were considered as homogeneous as in these cases both samples exhibited the same DNA ploidy; either both diploid or both hypodiploid. The remaining analysed tissues proved to be heterogeneous as they comprised both aneuploid and diploid types of cells. According to a general rule, these tumors were classified as aneuploid. Tumors classified as adenomas and carcinomas revealed more heterogeneous pattern of cellular DNA content than colloid and parenchymatous goitres. This proved again that for reliable evaluation of a lesion the samples from distinct parts of the tumor should be taken and analysed separately [32].

The cell cycle phase distribution did not show any correlation either with the percentage of cells in each phase of the cycle or histological type of examined thyroid lesions.
However, in goitres and adenomas, the mean values of proliferative index were significantly higher in aneuploid cell populations when compared with diploid ones. Increased proliferative activity in tissues with abnormal DNA content was also demonstrated by others [20,33, 34]. On the other hand, our results indicated that in carcinomas the mean PI values were significantly higher than in groups of benign thyroid lesions and were independent of DNA ploidy level.

The tissues collected and analysed in our study represented a variety of thyroid lesions. Moreover, some of the patients before thyreodectomy had undergone intensive pharmacotherapy with antithyroid medicines such as Methimazole, which could affect proliferative activity of thyroid cells [35]. For those reasons the interpretation of the compiled results would be possible only after examination of an extended group of patients, taking into account all parameters that could affect DNA ploidy and cell cycle kinetics.

Retrospective studies on paraffin-embedded tissues of all kinds of tumors are valuable. Comparability of the results obtained independently by different methods used in tissue processing seems to be a very important aspect, especially in thyroid neoplasms showing relatively low incidence. Kumar et al. [36] suggest that PI as well as DNA ploidy estimated in fixed tissue may not necessarily parallel the data obtained from fresh tumor specimen. According to others [37, 38], the values of DNA parameters seem to be comparable despite differences in storage conditions or the method of tissue preparation for analysis. However, single cell suspension retrieved from paraffin-embedded tissue may provide less precise results due to generation of cell degradation products (debris) and cell aggregates affecting the histogram. DNA content evaluation in paraffin-embedded tissues is supposed to be unreliable unless the tissue is properly fixed in $10 \%$ buffered solution of formalin, directly after resection [38]. According to our DNA study carried out on 26 tissues be- 
fore and after their treatment with formalin or paraffin, tissue processing seems not to have crucial influence on reliability of measurements performed on fixed material. The observed differences between samples were not significant and most probably resulted from local heterogeneity of the tumor. This was proved by low dispersion of DI values in 6 normal pig thyroid glands used as controls, subjected to similar fixation and preparation procedures. These results point to a possibility of using an archival material for flow cytometric DNA measurements.

\section{R E F E R E N C E S}

1. Abad, M., Ciudad, J., Rincon, M.R., Silva, I., Paz-Bouza, J.I., Lopez, A., Alonso, A.G., Bullon, A. \& Orfao, A. (1998) DNA aneuploidy by flow cytometry is an independent prognostic factor in gastric cancer. Anal. Cell Pathol. 16, 223-231.

2. Bakshi, N., Rajwanshi, A., Patel, F. \& Ganguly, N.K. (1998) Prognostic significance of DNA ploidy and S-phase fraction in malignant serous cystadenocarcinoma of the ovary. Anal. Quant. Cytol. Histol. 20, 215-220.

3. Rzymowska, J., Skierski, J., Kurylcio, L. \& Dyrda, Z. (1995) DNA index as prognostic factor in breast cancer. Neoplasma 42, 239-242.

4. Takanishi, D.M., Jr., Hart, J., Covarelli, P., Chappell, R. \& Michelassi, F. (1996) Ploidy as a prognostic feature in colonic adenocarcinoma. Arch. Surg. 131, 587-592.

5. Villanacci, V., Grigolato, P.G., Cadei, M., Cestari, R., Ravelli, P. \& Missale, G. (1998) Flow cytometry study of DNA and cell kinetics in the adenoma-carcinoma sequence in the large intestine. Pathologica 90, 120-126.

6. Resnik, E., Trujillo, Y.P. \& Taxy, J.B. (1997) Long-term survival and DNA ploidy in advanced epithelial ovarian cancer. J. Surg. Oncol. 64, 299-303.
7. Sampedro, A., Salas-Bustamante, A., LopezArtimez, M., Garcia-Muniz, J.L. \& Urdiales, G. (1999) Cell cycle cytometric analysis in the diagnosis and management of colorectal carcinoma. Anal. Quant. Cytol. Histol. 21, 347-352.

8. Vesalainen, S., Nordling, S., Lipponen, P., Talja, M. \& Syrjanen, K. (1994) Progression and survival in prostatic adenocarcinoma: A comparison of clinical stage, Gleason grade, S-phase fraction and DNA ploidy. Br. J. Cancer 70, 309-314.

9. Rice, T.W., Bauer, T.W., Gephardt, G.N., Medendorp, S.V., McLain, D.A. \& Kirby, T.J. (1993) Prognostic significance of flow cytometry in non-small-cell lung cancer. J. Thorac. Cardiovasc. Surg. 106, 210-217.

10. Salmon, I., Gasperin, P., Remmelink, M., Rahier, I., Rocmans, P., Pasteels, J.L., Heimann, R. \& Kiss, R. (1993) Ploidy level and proliferative activity measurements in a series of 407 thyroid tumors or other pathologic conditions. Hum. Pathol. 24, 912-920.

11. Genest, D.R., Sheets, E. \& Lage, J.M. (1994) Flow cytometric analysis of nuclear DNA content in endometrial adenocarcinoma. Am. J. Clin. Pathol. 102, 341-348.

12. Ikonen, J.T., Ojala, A., Salenius, J.P., Mattila, J., Riekkinen, H. \& Wigren, T. (1999) DNA flow cytometry in surgically treated lung cancer - prognostic significance. Scand. Cardiovasc. J. 33, 228-233.

13. Leivonen, M., Krogerus, L. \& Nordling, S. (1994) DNA analysis in advanced breast cancer. Cancer Detect. Prev. 18, 87-96.

14. Ottesen, G.L., Christensen, I.J., Larsen, J.K., Kerndrup, G.B., Hansen, B. \& Andersen, J.A. (1995) DNA aneuploidy in early breast cancer. Br. J. Cancer 72, 832-839.

15. Treseler, P.A. \& Clark, O.H. (1997) Prognostic factors in thyroid carcinoma. Surg. Oncol. Clin. N. Am. 6, 555-598. 
16. Schurmann, G., Mattfeldt, T. \& Feichter, G. (1991) Stereology, flow cytometry and immunohistochemistry of follicular neoplasms of the thyroid gland. Hum. Pathol. 22, 179-184.

17. Simpson, W.M. (1976) Three cases of thyroid metastasis to bones with a discussion as to the existence of the so-called "benign metastasing goitre”. Surg. Gynecol. Obstet. 42, 489-507.

18. Francia, G., Azzolina, L., Mantovani, T. \& Davi, M. (1997) Heterogeneity of nuclear DNA pattern and its relationship with cell cycle activity parameters in multinodular goitre. Clin. Endocr. 46, 649-654.

19. Cusick, E., Ewen, S., Krukowski, Z.H. \& Matheson, N.A. (1991) DNA aneuploidy in follicular thyroid neoplasia. Br. J. Surg. 78, 94-96.

20. Harlow, S.P., Duda, R. \& Bauer, K.D. (1992) Diagnostic utility of DNA content flow cytometry in follicular neoplasms of the thyroid. J. Surg. Oncol. 50, 1-6.

21. Hoestetter, A.L., Hrafnkelsson, J. \& Sten, M.D. (1988) A comparative study of cytometry methods for benign and malignant thyroid tissue. Am. J. Clin. Pathol. 89, 760-763.

22. Joensuu, H., Klemi, P., Eerola, E. \& Tuominen, J. (1986) Influence of cellular DNA content on survival in differentiated thyroid cancer. Cancer 58, 2462-2467.

23. Joensuu, H., Klemi, P. \& Schluter, G. (1986) DNA aneuploidy in follicular adenomas of thyroid gland. Am. J. Pathol. 124, 373-376.

24. Kraemer, B.B., Srigley, J.R., Silva, E.G. \& Goepfert, H. (1985) DNA flow cytometry of thyroid neoplasms. Arch. Otolaryngol. 111, $34-38$.

25. Onaran, Y., Tezelman, S., Gurel, N., Terzioglu, T., Oguz, H., Tanakol, R. \& Kapran, Y. (1999) The value of DNA content in predicting the prognosis of thyroid carcinoma in an endemic iodine deficiency region. Acta Chir. Belg. 99, 30-35.

26. Hedley, D.W., Friedlander, M.L., Taylor, J.W., Rugg, C.A. \& Musgrove, E.A. (1983) Method for analysis of cellular DNA content of paraffin-embedded pathological material using flow cytometry. J. Histochem. Cytochem. 31, 1333-1335.

27. Skierski, J.S., Koronkiewicz, M. \& Grieb, P. (1999) Effect of FMdC on the cell cycle of some leukemia cell lines. Cytometry 37, 302-307.

28.Stern, Y., Lisnyanski, I., Shpitzer, T., Nativ, O., Medalia, P., Feinmesser, R. \& Aronson, M. (1997) Comparison of nuclear DNA content in locally invasive and noninvasive papillary carcinoma of the thyroid gland. Otolaryngol. Head Neck Surg. 117, 501-503.

29. Nakada, K., Katoh, C., Morita, K., Kanegae, K., Tsukamoto, E., Shiga, T., Mochizuki, T. \& Tamaki, N. (1999) Relationship among 201T1 uptake, nuclear DNA content and clinical behavior in metastatic thyroid carcinoma. $J$. Nucl. Med. 40, 963-967.

30.McLeod, M.K., Thompson, N.W., Hudson, J.L., Gaglio, J.A., Lloyd, R.V., Harness, J.K., Nishiyama, R. \& Cheung, P.S. (1988) Flow cytometric measurement of nuclear DNA and ploidy analysis in Hürthle cell neoplasms of thyroid. Arch. Surg. 123, 849-853.

31. Horii, A., Yoshida, J., Sakai, M., Okamoto, S., Honjo, Y., Mitani, K., Hattori, K. \& Kubo, T. (1999) Ki-67 positive fractions in benign and malignant thyroid tumors: Application of flow cytometry. Acta Otolaryngol. 119, 617-620.

32. Bergers, E., van Diest, P.J. \& Baak, J.P. (1996) Tumor heterogeneity of DNA cell cycle variables in breast cancer measured by flow cytometry. J. Clin. Pathol. 49, 931-937.

33. Roseano, M., Turolado, A., Balani, A., Tonello, C., Desinan, L. \& Bussani, R. (1994) DNA ploidy and cell kinetics in cancer of the rectum. Ann. Ital. Chir. 65, 319-329. 
34. Krygier-Stojałowska, A., Urasiński, J., Kuchnio, M. \& Gapski, Z. (1993) DNA-ploidy in non Hodgkin's lymphomas of low malignancy. Acta Haem. Pol. 24, 153-159.

35. Smerdely, P., Pitsiavas, V. \& Boyages, S.C. (1993) Methimazole inhibits FRTL5 thyroid cell proliferation by inducing S-phase arrest of the cell cycle. Endocrinology 133, 2403-2405.

36. Kumar, D., Kumar, S. \& Lyon, D. (1994) Comparison of flow cytometric DNA content analysis of fresh and formalin-fixed paraffin-embedded solid neoplasms. Mod. Pathol. 7, 354-360.
37. Chen, T.L., Luo, I., Mikhail, N., Raskova, J. \& Raska, K., Jr. (1995) Comparison of flow and image cytometry for DNA content analysis of fresh and formalin-fixed, paraffin-embedded tissue in breast carcinoma. Cytometry 22, 181-189.

38. Niezabitowski, A., Lachowska, B., Rys, J., Dyba, T., Gruchala, A., Szklarski, W., Stelmach, A., Kurczak, A. \& Swiatkiewicz, I. (1994) Comparative flow cytometric DNA analysis on fresh and paraffin-embedded tumor tissue in different neoplasms. Pol. J. Pathol. 45, 203-208. 